\title{
Identifying the Knowledge Requirements of a New Project Entrant: An Informing Science Approach
}

\author{
Grafton Whyte and Desire Minnaar \\ Harold Pupkewitz Graduate School of Business, \\ Polytechnic of Namibia, Windhoek, Namibia
}

\author{
drgwhyte@live.com; desire.minnaar@gmail.com
}

\begin{abstract}
IT projects fail for many reasons. Often this is attributed to poor project management; however, knowledge, though a critical resource within organizations and projects, is often overlooked as a cause of project failure. Changes to project teams can affect the knowledge balance within the team and new entrants often have to learn large amounts of information before actively contributing to the project. This research sought to identify the knowledge requirements of new project entrants to enable them to become productive sooner. It also investigated the Inkwenkwesi knowledge model as a framework for defining the knowledge requirements of new project entrants.

Employing a novel research approach, the study identified knowledge that was needed prior to starting on the project and knowledge needed during the project, which all contributed positively to the new entrant becoming productive more quickly on a project. The study also concluded that the Inkwenkwesi knowledge model was useful for defining the knowledge needed by new project entrants.
\end{abstract}

Keywords: Inkwenkwesi knowledge model, project knowledge, project requirements, new project entrant, informing science

\section{Introduction}

IT project failures are often attributed to poor project management practices and poor change management. Knowledge management is, however, often overlooked as a cause of project failure. Knowledge has been identified as a critical resource within organisations and the management thereof can contribute to project success. Projects are made up of project teams with the purpose of achieving an objective, product, or service within a defined scope and time frame. Managing IT projects is a complex endeavor where success has often proved elusive, a recent Chaos report (Standish Group International, 2012) suggests that as many as $80 \%$ of IT projects either fail or are

Material published as part of this publication, either on-line or in print, is copyrighted by the Informing Science Institute. Permission to make digital or paper copy of part or all of these works for personal or classroom use is granted without fee provided that the copies are not made or distributed for profit or commercial advantage AND that copies 1) bear this notice in full and 2) give the full citation on the first page. It is permissible to abstract these works so long as credit is given. To copy in all other cases or to republish or to post on a server or to redistribute to lists requires specific permission and payment of a fee. Contact Publisher@InformingScience.org to request redistribution permission. completed seriously impaired. We may debate what is actually meant by projects failing or being seriously impaired. Is it to miss critical deadlines, or significantly over-run budget, or deliver substantially less user functionality than originally agreed? The fact is this level of delivery is problematic and testifies of the complexity associated with delivering IT projects. Indeed IT project delivery exhibits all of the complexity at- 
tributes identified by Campbell (1998) and revised by Gill (2011), of outcome multiplicity, solution theme multiplicity, conflicting interdependence, and outcome uncertainty.

Much research has been done investigating why projects, and IT projects in particular, fail with such great regularity. However, very few of these papers have investigated the problem from a knowledge management perspective (Disterer, 2002; Faraj \& Sproull, 2000; Kasvi, Vartiainen, \& Hailikari, 2003; Tiwana, Bharadwaj, \& Sambamurthy 2003; Yoo \& Kanawattanachai 2001). This paper takes a knowledge management approach to the complex problem of managing IT projects. Specifically we investigate the problem from the unique perspective of new members joining a project team, who often have to acquire large amounts of information and knowledge before being able to actively contribute to the project team. This delay in becoming effective is bad enough on its own, but is compounded by the fact that often the knowledge that new project entrants need to acquire can only come from existing team members, which then impedes their performance and the overall productivity of the project. Often all of this is taking place against a background where the project is already running late.

In this paper we introduce the Inkwenkwesi knowledge (Ink) model as a framework for understanding the high-level knowledge domains present for typical organisations and, by inference, projects. It based on early research work completed by Whyte (1994), where he demonstrates how these knowledge domains (elements) influence perceptions of the success or failure of organisational information systems.

Galloway and Whyte (1988) argue that perceptions of the success or failure of an information system has less to do with the technicalities of that system but how well system managers are able to match user expectations to the service being delivered; this is accomplished through the management of uncertainty and internal-consistency between key elements in the system. These elements being identified in this early study as service staff, management, the product and the process.

This idea was developed further in a later study by Whyte (1994), he argued that elements of service in the preceding discussion seem to be those which are essential to the provision of information system services and projects and, therefore, could be extended to include the following: service product, which is the substance or object of the service; the service process, which is the process of creating and delivering the product to the user; the customer (or user) who is an integral part of the service delivery process; staff who are both the service providers involved in delivering the service and service managers responsible for managing the service operation; and the organisation which provides the context and setting in which the service operates.

Evidence collected by Whyte (1994) demonstrated that the following service elements have important influence on the success of a service, these are:
- Product
- Process
- Customer
- Staff
- Organisation

In the Ink model, this work is built upon by arguing that these elements are (i) important domains of knowledge in the context of a organisation and (ii), when service, suppliers and environment are added to these elements, the model provides a holistic and, arguably, universal knowledge perspective of an organisation and provides a framework for understanding the knowledge requirements of new project entrants (Whyte, 2011; Whyte \& Minnaar, 2013). Inkwenkwesi is Xhosa for star and recognises the contribution made by South Africa to the development of this thinking. 
In addition to the knowledge management approach this paper takes an informing science approach to managing IT projects. In Figure 1 below we present a simple informing system for IT projects.

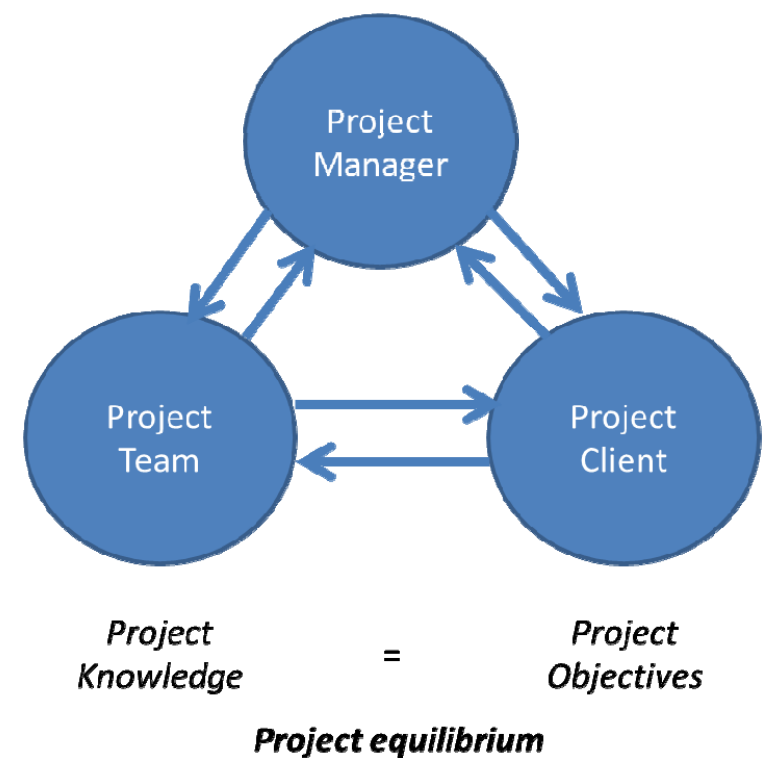

Figure 1: A simplified informing system for IT project management (adapted from Montiel, 2013)

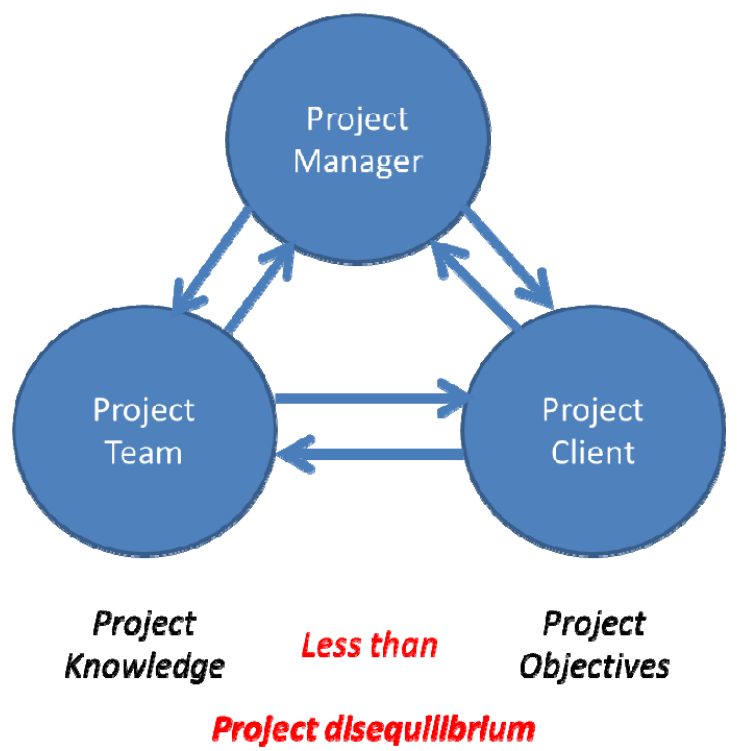

Figure 2: A simplified informing system for an IT project when in disequilibrium

In this simple informing model it is suggested that an IT project comprises three core parties: the project client who are the owners of the project objectives, the project team who possess the knowledge required to fulfill the project objectives, and the project manager who focuses and mediates between the other two parties to ensure the project objectives are met. At a simple level the model suggests that projects are successful when there is equality between the knowledge of the project team and the objectives of the project. Here knowledge would be defined as the ability 
to deploy skills, expertise, and resources to meet the cost, quality, and timing objectives of the project. Where the knowledge of the project team is less than that required to meet the project objectives, as in Figure 2, the project is in disequilibrium and if left unchecked will cause the project to fail. Therefore a key role of the project manager is to ensure this project equilibrium is maintained.

The response of the project manager is to restore the equilibrium of the project either by reducing the scope of the project objectives or by increasing the project knowledge. Figure 3 demonstrates what potentially takes place when the project manager seeks to restore the project equilibrium by introducing a new entrant to the project team especially in the latter critical stages of a project.

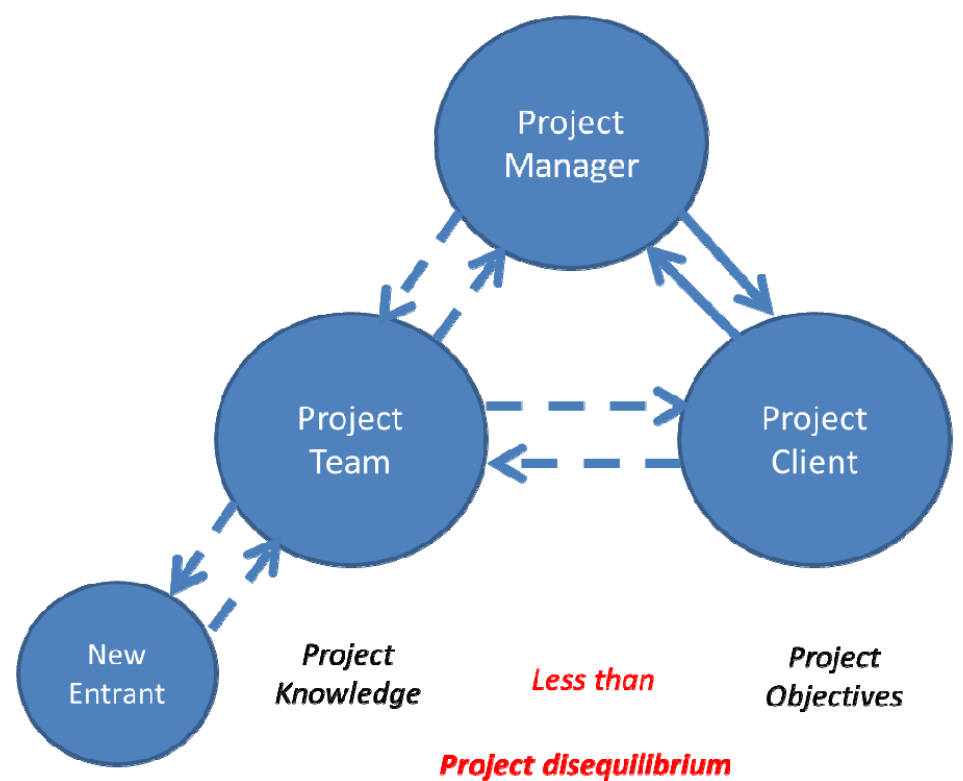

Figure 3: A simplified informing system for an IT project when a new entrant is introduced

In informing terms, an added burden is placed on the project team, which now has to bring the new entrant up to speed in terms of the knowledge required to fully integrate the person into the project team to a point where they are productive. This informing burden may also extend to the client and project manager, represented by the broken arrows. This additional informing burden may exacerbate the project disequilibrium until the new entrant has become fully absorbed into the project team

This research therefore has two broad goals:

1) Identify the knowledge requirements of new project entrants that will enable them to become productive sooner and,

2) Test the Inkwenkwesi knowledge model as a tool for defining the knowledge new project entrants require to become productive sooner when joining a project.

Using a novel methodological approach this research identifies knowledge that a new project entrant needs to acquire prior to joining an IT project team to become productive sooner and knowledge that needs to be acquired after joining the team as quickly as possible. The research also confirms the usefulness of the Ink model as a means of identifying knowledge domains.

This paper is structured as follows. In the next section the literature is reviewed with respect to types of knowledge that occur within a project. The Inkwenkwesi knowledge model is introduced and the research design and methodology discussed. The results and findings are presented and finally some recommendations are made. 


\section{Literature Review}

Large amounts of research exist that describe reasons for Information Technology project failures (C. Chan, Jiang, \& Klein, 2008; Kang \& Hahn, 2009; Karlsen \& Gottschalk, 2004; Reich, 2007). These include, but are not limited to, a lack of project management and processes, inadequate scope and change management (Reich, 2007). Knowledge management, however, has been overlooked as a cause of project failure (Disterer, 2002). In support of this view, it has been shown that effective knowledge management increases the likelihood of project success (Faraj \& Sproull, 2000). Yoo and Kanawattanachai (2001) demonstrate that the coordination and management of knowledge between different teams has a strong influence on the success of a project. Tiwana et al. (2003) also report that knowledge integration is of greater importance to project success than the relationships between IT project teams and the business. Kasvi et al. (2003) remark that, in addition to competence, project success is dependent on accumulated, collective, and individual knowledge. It's important to note here that our attention is drawn to the fact that both individual and collective competence is required for success. C. Chan et al. (2008) reinforce this statement, saying that skills possessed by team members are critical for success.

\section{Knowledge within a Project}

The literature refers to four main types of knowledge critical to IT projects. These are Project Management knowledge, Business Domain knowledge, Technical knowledge, and Institutional knowledge.

\section{Project management knowledge}

Project Management Knowledge refers to the knowledge of coordinating, planning, and managing the various IT project activities (Zhao \& Zuo, 2011). It involves the planning, organizing, controlling the project, and managing project risk, in order to meet the project objectives within various time and budget constraints (R. Chan \& Rosemann, 2001; Goles, Hawk, \& Kaiser, 2008). Reich (2007) refers to this as process knowledge in her research. It is the knowledge about project time frames, tasks, processes, methodologies, and project structure. This knowledge clarifies what is expected from each team member within the project and associated timelines. C. Chan et al. (2008) place great emphasis on team task, coordination skills, and knowledge. They state that this knowledge is more important and has a greater impact on project success than application domain and development method knowledge. Research done by Goles et al. (2008) has found that project management skills and knowledge are one of the highest ranked skills for IT firms today.

\section{Business domain knowledge}

The second type of knowledge is Business Domain Knowledge. This refers to knowledge about the "customer" organisation that the IT project is delivering to. It includes knowledge about the business processes, rules, activities, functional areas, entities, business operations and policies, customer business objectives, and stakeholder needs (R. Chan \& Rosemann, 2001; Kang \& Hahn, 2009; Lee, Trauth, \& Farwell, 1995; Tiwana, 2004; Zhao \& Zuo 2011). Reich (2007) expands on this and states that it includes knowledge about the industry and the business opportunity or problem currently at hand. Current project members would have a good understanding of the organisation and its processes; however, this may be a gap for a new member joining the project. Kang and Hahn (2009) stress the importance of domain knowledge, stating that without it the project team would not know what to build in the IT solution. Business domain knowledge includes the ability to integrate business needs with technology and thus requires the knowledge of functional area processes and business process design in order to meet the needs of the organisation (C. Chan et al., 2008; Goles et al., 2008). 


\section{Technical knowledge}

The third category of knowledge is Technical knowledge. Zhao and Zuo (2001, pp. 268) refer to this as project engineering knowledge. This knowledge refers to the technical know-how to implement information systems and the activities involved in the systems development life cycle (Goles et al., 2008; Zhao \& Zuo, 2001). This category of knowledge is IT specific, i.e., what the various technologies are and how they are implemented.

\section{Institutional knowledge}

The last major knowledge category critical to IT projects is Institutional knowledge. This knowledge refers to the history and values of the organisation. Reich (2007) advises that institutional knowledge is not so much about the facts of the organisation, but rather about how facts are to be interpreted to understand "what is really going on". R. Chan \& Rosemann (2001) refer to this as company-specific knowledge. In their research on managing knowledge of enterprise systems they claim that systems cannot be successfully implemented without taking individual companyspecific factors into accounts. Company-specific knowledge includes values, culture, staff morale, behavior, and attitudes within the organisation.

\section{Overview of Knowledge Types}

Software development is a knowledge intensive process. It requires specialized knowledge in many domains to conceptualize and design software solutions that meet business needs (Kang \& Hahn, 2009). A study conducted by Tiwana (2004) concluded that high levels of knowledge integration contributes positively and influences the success of software development. Business and Technical domain knowledge needs to be integrated to improve effectiveness and efficiency of software development.

Reich (2007) advises that knowledge integration can benefit project performance and is crucial when a projects attempts to solve difficult problems. On the other hand, she suggests that process and domain knowledge are the most important knowledge areas for project team members. Kang and Hahn (2009) indicate that acquiring technology and methodology knowledge precedes domain knowledge; in other words, an individual would acquire technology and methodology knowledge before acquiring domain knowledge. Kang and Hahn (2009) refer to methodology knowledge as the knowledge related to the process of managing a software project, referred to in this paper as Project Management knowledge. According to C. Chan et al (2008) team task skills, here classified as Project management knowledge, are more critical than other skills in a project. Goles et al. (2008) focused their research on the most critical IT knowledge required by organisations today and into the future. Their findings reflect that Project Management knowledge, specifically project planning, budgeting, and scheduling, was ranked the highest critical skills for IT firms. It was clear from the findings that Technical knowledge did not appear to be critical to IT firms.

\section{Inkwenkwesi Knowledge Model}

The Inkwenkwesi knowledge (Ink) model, proposed by Whyte (2011), postulates a holistic knowledge view of an organisation. The Ink model identifies five key knowledge domains within the boundary of the organization and three outside. The five domains of knowledge internal to the organisation are People, Process, Organisation, Product, and Service. Suppliers, Customers, and the External Environment are the knowledge domains outside of the organisation boundary. The interrelationship of these domains is represented in Figure 4 below. 


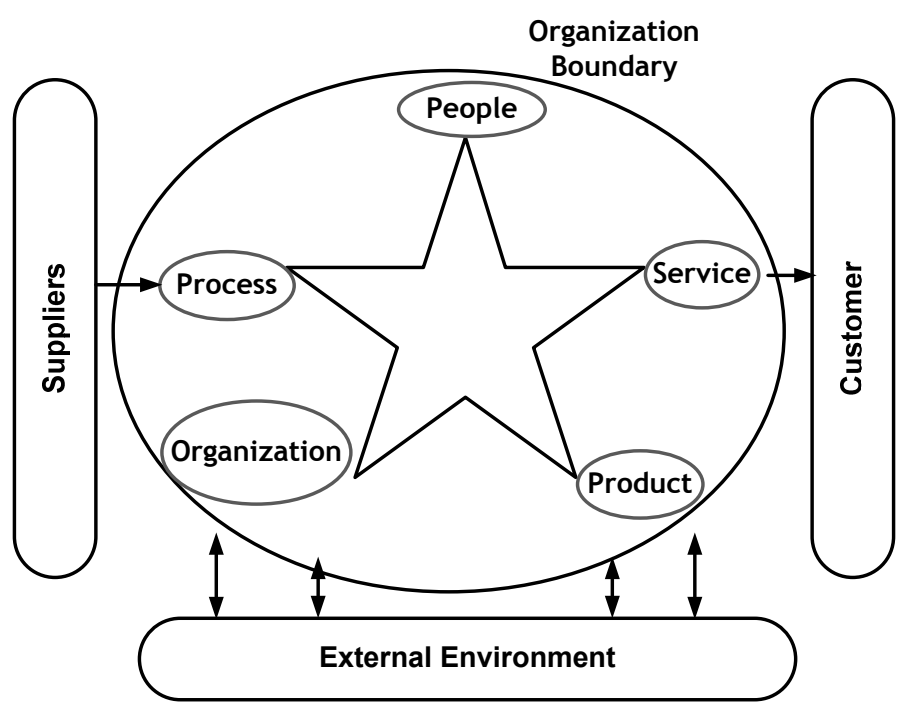

Figure 4: Inkwenkwesi knowledge model (Whyte, 2011)

It is suggested that all knowledge artifacts pertaining to an organisation can be uniquely classified under two or more of these knowledge domains, e.g., an HIV vaccination programme will be classified as a service delivered to customers in a particular location, the programme will be comprised of certain processes and involve certain key people. In this way the knowledge of managing a health vaccination programme can be retained and be made available for retrieval and sharing using this simple schema.

The following is a list of the knowledge domains and definitions in the Ink model

- Service This knowledge refers to the knowledge of the services being delivered to the organisation by the project.

- Product This knowledge refers to the knowledge of the product being delivered by the project within the organisation.

- Process This knowledge refers to the knowledge of the project processes to be adhered by the project within the organisation.

- People This knowledge refers to the knowledge of important project and business stakeholders.

- Organisation This knowledge refers to the knowledge of where in the organisation things are done or knowledge is kept.

- Supplier This knowledge refers to the knowledge of any suppliers, third party vendors or service providers delivering a product/service to the project.

- Customer This knowledge refers to the knowledge of the various customer groups for whom the project is being delivered.

- Environment This refers to knowledge of the macro environment, (e.g. Industry \& Market) in which the project operates within the organisation.

Returning to the problem of managing IT projects, a project team can be viewed as a micro organisation. The organisation boundary in the Ink module thus refers to the boundary of the project and project team. With this in mind, the five internal knowledge domains thus highlight the various kinds of knowledge that exist within an IT project team. One aim of the research was to determine how useful is the Ink model as a means of defining the knowledge requirements of a new 
project entrant. Clearly, from the definitions offered by the two lists there is a degree of overlap, e.g., Business Domain with Customer, and Institutional Knowledge with Organisation. However, the two lists of domains appear more complimentary as the project management domains have a more inward-looking perspective focusing on the project management process whereas the Ink model is clearly taking a more outward-looking perspective.

In summary the potential areas of knowledge for a new project entrant and their sources are listed in Table 1.

Table 1: Summary of knowledge domains

\begin{tabular}{|c|}
\hline Project Management Literature \\
\hline Project Management \\
\hline Business Domain \\
\hline Technical knowledge \\
\hline Institutional knowledge \\
\hline Inkwenkwesi knowledge (Ink) model \\
\hline Service \\
\hline Product \\
Process \\
People \\
Organisation \\
Supplier \\
Customer \\
Environment
\end{tabular}

\section{Research Design and Methodology}

In Table 1 several knowledge types have been identified in the literature. The four broad knowledge categories include Project Management, Business Domain, Technical, and Institutional knowledge. The Ink model identifies a further eight (8) knowledge types. Five (5) within the boundary of the project, i.e., Service, Product, Process, People, and Organisation knowledge, and three (3) outside of the project boundary, i.e., Environmental, Supplier, and Customer. Altogether these twelve knowledge types are tested to understand the relationships that may exist between the perceived level of the respective knowledge types acquired by the new project entrant and the perceived rate at which the individual felt productive within the project. Pearson's correlations were calculated between the level of knowledge acquired for the respective knowledge types and the perceived time to becoming productive on the project. Furthermore the study aims to identify which knowledge types have a greater impact on the rate of productivity and whether these knowledge types can be mapped against the Ink model. For this purpose a survey questionnaire was the chosen method for answering the research questions.

The research survey (Appendix) consisted of four (4) open-ended questions and thirteen (13) close-ended questions. Twelve (12) of the thirteen (13) close-ended questions were based on the twelve (12) knowledge types. For each of these knowledge types, the respondents were required 
to rate their level of knowledge before they were productive on the project as well as after they were productive on the project, in the form of a Likert scale ranging from 1 (Poor Knowledge) to 7 (Strong Knowledge). Two values were thus captured per knowledge type. Respondents were allowed to define for themselves the stage at which they perceived themselves to have become productive and were only guided by the survey instructions that it represented the point at which the entrant had sufficient knowledge to make a positive contribution to the project. The last closeended question required respondents to rate the overall time it took them to become productive on the project, again ranging from 1 (Very Slowly) to 7 (Very Quickly).

\section{Research Sample}

The target population in this study included IT staff that had just joined an IT project within an environment unfamiliar to them. In other words, specifically project members that had recently joined a project that was new to them and therefore caused them to experience some level of discomfort due to a lack of knowledge at the point of joining the project, thus impacting on their performance and productivity.

The sample selected for this study consisted of IT professionals employed by a leading South African insurance company that had been working on projects within the IT industry. A total of 50 IT professionals were surveyed, of which 45 responses were collected and analyzed, resulting in an acceptance rate of $90 \%$. The sample included a variety of IT roles, i.e., project managers, developers, architects, and business analysts.

\section{Instrument Design and Collection Method}

An online web-based survey tool was used to create the survey. An email including a summary of the research objective and a website link to the online survey was sent to IT professionals employed by the IT department. The website link in the body of the email directed respondents to an intranet SharePoint website. All responses were recorded online, exported to an excel spreadsheet, and prepared for analysis.

\section{Survey Reliability}

Reliability is defined as the degree to which the survey provides stable and consistent results under similar conditions (Litwin, 1995). It is the measure of stability when the measurement is repeated in an identical population. The Test-retest reliability assessment was applied to test the reliability of the survey. The survey was completed on two occasions, two months apart, by a pilot test group. The reliability assessment was calculated using Cronbach's Alpha'. The Cronbach's Alpha was calculated for all the questions, i.e., twelve knowledge types (for before and after productivity) and one question based on the time-to-productivity. A Cronbach's Alpha of .98 was calculated, demonstrating a high degree of reliability and internal consistency. According to DeVellis (2003), reliability is considered to be good if alpha values are greater than or equal to 0.7 .

\section{Results and Discussion}

The Pearson's correlation coefficient calculation was used to determine the correlation coefficient between the twelve knowledge types and the time to productivity. It was first calculated for the before-productivity knowledge value to time-to-productivity, and thereafter for the afterproductivity knowledge value to time-to-productivity. The twelve knowledge types were analysed and are reported in three categories; 
1) During the project knowledge types - these are knowledge types that showed a positive correlation as knowledge acquired during the project which contributed to the productivity of the new project entrant,

2) Prior to project knowledge types - these are knowledge types that showed a strong correlation as knowledge acquired prior to the project which contributed to the productivity of the new project entrant and,

3) Insignificant knowledge types - these are knowledge types that seemed not to have a strong correlation at any stage of the project and did not seem to contribute positively to the productivity of the new entrant.

\section{Presentation and Discussion}

Table 2 illustrates the correlation and significance p-values for each of the knowledge types as a result of the data analysis process completed. Values displayed are for before-productivity and after-productivity on the project. All before-productivity and after-productivity values are correlated to the time-to-productivity and classified according to their respective categories.

Table 2: Pearson Correlation and Significance values

\begin{tabular}{|c|c|c|c|c|}
\hline \multirow[t]{2}{*}{ Knowledge Type } & \multicolumn{2}{|c|}{$\begin{array}{l}\text { Before-productivity } \\
\text { (Correlated to time-to-productivity) } \\
\qquad(N=45)\end{array}$} & \multicolumn{2}{|c|}{$\begin{array}{l}\text { After-productivity } \\
\text { (Correlated to time-to- } \\
\text { productivity) } \\
(\mathrm{N}=45)\end{array}$} \\
\hline & Pearson Correlation & Significance & $\begin{array}{c}\text { Pearson Correla- } \\
\text { tion }\end{array}$ & Significance \\
\hline \multicolumn{5}{|c|}{ 'During the Project' Knowledge Types } \\
\hline Customer & 0.27 & 0.04 & 0.38 & 0.01 \\
\hline Service & 0.34 & 0.01 & 0.36 & 0.01 \\
\hline Supplier & 0.38 & 0.01 & 0.4 & 0 \\
\hline \multicolumn{5}{|c|}{ Prior to Project Knowledge Types } \\
\hline Technical & 0.59 & 0 & 0.47 & 0 \\
\hline Process & 0.44 & 0 & 0.39 & 0 \\
\hline People & 0.46 & 0 & 0.34 & 0.01 \\
\hline Project Management & 0.45 & 0 & 0.11 & 0.23 \\
\hline Organisation & 0.42 & 0 & 0.14 & 0.18 \\
\hline \multicolumn{5}{|c|}{ Insignificant Knowledge Types } \\
\hline Business Domain & 0.22 & 0.07 & 0.14 & 0.17 \\
\hline Product & 0.18 & 0.12 & 0.19 & 0.11 \\
\hline Environmental & 0.16 & 0.14 & 0.23 & 0.06 \\
\hline Institutional & 0.09 & 0.28 & -0.08 & 0.29 \\
\hline
\end{tabular}

\section{During the Project' knowledge types}

The first category, 'During the Project' knowledge types, consists of Customer, Service, and Supplier and are the only knowledge types with an after-productivity correlation greater than the before-productivity correlation to time-to-productivity and are also statistically significant, suggesting that not only do these knowledge types contribute positively to the new entrant's time to 
productivity, but they increase over time (denoted by the increase in the correlation coefficient values) as the new entrant acquires more knowledge in these areas during the project.

The Customer before-productivity to time-to-productivity relationship is considered a weak positive relationship, (coefficient of 0.27). The Customer after-productivity to time-to-productivity relationship is, however, strengthened and considered to be a moderately positive relationship (correlation of 0.38). The increase from before-productivity to after-productivity correlations indicates that it is the Customer Knowledge gained during the project which may result in reduced time to productivity, since the relationship to the time it takes to become productive is strengthened for customer knowledge gained during the process of becoming productive. Customer knowledge also reflects the greatest increase (from 0.27 to 0.38 ) for knowledge types in the 'During the project' category.

Supplier and Service knowledge also reflect a greater after-productivity correlation to time-toproductivity compared to the before-productivity correlation, meaning that the supplier and service knowledge gained during the process of becoming productive on the project may result in faster times to productivity for the new project entrant. An increased after-productivity correlation with time-to-productivity value reflects that the Supplier and Service knowledge gained during the project may have a greater positive impact on the time to productivity for the new entrant compared to the existing supplier knowledge the new entrant entered into the project with.

\section{'Prior to Project' knowledge types}

The 'Prior to Project' knowledge types is made up of Technical, Process, People, Project Management and Organisation knowledge.

Before Productivity. These five knowledge types have been categorized together for two main reasons. Firstly, the before-productivity values of these five knowledge types have a strong positive relationship with the time-to-productivity. (Correlations values are greater than 0.4.) The second reason for this classification is that the after-productivity value for these five knowledge types has a weaker, although positive, correlation to time-to-productivity. This means, that it is the Technical, Process, People, Project Management, and Organisation knowledge that the project entrant entered into the project with, i.e., knowledge gained prior to joining the project, that may result in the new entrant becoming productive faster. These relationships are also statistically significant since their $\mathrm{p}$-values are less than 0.05 .

After Productivity. The after-productivity values correlations to time-to-productivity are less than the before productivity correlations for these five knowledge types. This indicates that these knowledge types may have had a positive impact on time-to-productivity, but not as great as the knowledge acquired prior to joining the project. In other words, it's the knowledge gained prior to joining the project that may have a greater positive impact on the time it takes the new entrant to become productive, than the knowledge gained during the project in these areas.

Only Technical, Process, and People knowledge types have a moderately positive to strong positive relationship with the time it takes to become productive. Although these relationships are not as strong are their respective before-productivity values, they are statically significant.

Project Management and Organisation knowledge gained during the project, however, reflect a negligible relationship to time-to-productivity. These relationships are not statistically significant. The Project Management and Organisation knowledge gained prior to the project share a significant and strong positive relationship to the time it takes the new entrant to be productive. The knowledge gained during the project in these areas, however, is shown to be insignificant and makes very little difference to how soon the project entrant becomes productive. 


\section{'Insignificant' knowledge types}

Business Domain, Product, Environment, and Institutional knowledge types are classified in this study as insignificant knowledge types. These knowledge types reflect negligible or no relationship to the time it takes to become productive. This applies to knowledge gained prior to joining the project and during the project. Knowledge gained in these areas seems to have very little impact on the time the new entrant felt it took to become productive on the project. The relationship between the knowledge gained prior to and during the project to the amount of time it took the new entrant to become productive on the projects are not only weak or non-existent, but also not statically significant.

\section{Inkwenkwesi Knowledge Model Analysis}

This section maps how well the Ink model identifies the knowledge types required by the new project entrant in order to become productive sooner. The Ink model includes eight of the twelve knowledge types used for analysis in this research.

\section{'During the project' knowledge types}

All the knowledge types classified as 'During the Project' knowledge types, i.e., Customer, Service, and Supplier, are included in the Ink model. These three knowledge types were the only ones identified, as speeding up the process of becoming productive during the project when acquired during the project. Figure 5, illustrates these knowledge types as mapped on the Ink model. The knowledge types highlighted in green on the Ink model make reference to the 'During the Project' Knowledge types, as found on the Ink model. In this regard, the Ink model identifies all the knowledge types a new project entrant requires during the project in order to become productive sooner.

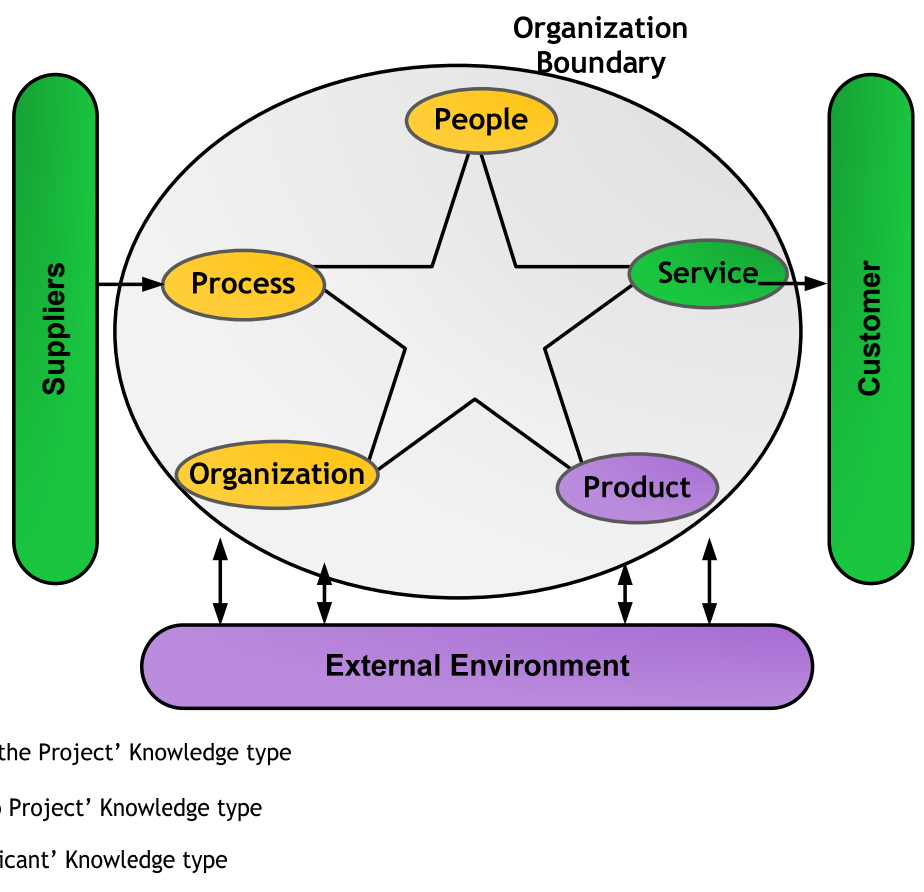

Figure 5: Inkwenkwesi Model with classified knowledge types 


\section{'Prior to project' knowledge types}

The knowledge types highlighted in Orange in Figure 5 illustrate the 'Prior to Project' Knowledge types found on the Ink model. In the previous section, Technical, Process, People, Project Management. and Organisation were identified as 'Prior to Project' knowledge types. The Ink model identifies three, People, Process, and Organisation knowledge. Technical and Project management knowledge are the two 'Prior to Project' knowledge types not included in the Ink model.

\section{'Insignificant knowledge types}

Business Domain, Product, Environment, and Institutional knowledge were identified as insignificant knowledge types. Figure 5 highlights the insignificant knowledge types included in the Ink model in purple. The Ink model consists of two insignificant knowledge types. These are Environment and Product knowledge.

Overall the Ink model is shown to be a good model for identifying the knowledge types required by a new project entrant in order to get productive sooner and justifies further investigation. All 'During the project' knowledge types are included in the Ink model. These identify the knowledge requirements during the project. Three of the five orange types, 'Prior to Project' knowledge types, are included in the Ink model. These are knowledge types identified as knowledge to be gained prior to joining the project in order to become productive sooner, and lastly only two out of four insignificant knowledge types are included in the Ink model. Overall this makes for a good model to be used to identify the knowledge types of a new project entrant.

\section{Recommendations}

Based on this research, the following recommendations can be made to organisations that run IT projects.

- The results seem to suggest that an enquiry based on knowledge areas and IT project management is a fruitful line of enquiry. Clearly there seems to be a link between knowledge domains and the ability of IT professionals to become productive sooner. From an informing science perspective the results suggest that when projects are approaching disequilibrium project managers should be engaging in a wider discussion with clients and the project team. This discussion should include identifying other knowledge areas that might be key to the project rather than simply a narrow (and more common) discussion about IT skills.

- Project managers can use the Ink model with the classified knowledge types to identify the knowledge types required during the project for any new persons joining the project. If project managers focus on ensuring knowledge about the Customer, Supplier, and Service are shared with new project members early in the project; it may result in new members becoming productive sooner.

- The Ink model, with the classified knowledge types, may also be used during the process of selecting project members to join a project. 'Prior to Project' knowledge types have been shown to be associated with reduced times to productivity. Although the Ink model only includes three of the five Prior to Project' knowledge types, i.e., Process, People and Organisation, there may be merit in including these knowledge areas as part of the selection criteria when identifying potential candidates for projects. Ensuring the potential candidates also have People, Process, and Organisation knowledge prior to joining the project may reduce times to productivity for the potential candidate.

- The Ink model with the classified knowledge types may be used to identify knowledge gaps within the existing project team. Productivity may be increased in the project teams 
if the reason for lowered productivity is as a result of a lack of knowledge in the team. The Ink model with the classified knowledge types may be used to assess the collective project knowledge that exists in the team and identify weaker knowledge areas that need to be addressed, in order to increase productivity.

- From a researcher perspective it follows from the limitations identified earlier that the results of this study need to be verified by drawing a wider sample of IT personnel from multiple organisations and industries and selecting only those IT personnel who had recently joined an IT project as new entrants in the previous two years. These measures would provide a more robust sample and a further test of the original research question.

\section{Conclusion}

This research had two objectives:

1) Identify the knowledge requirements of a new project entrant which will enable them to become productive sooner and,

2) Test the Inkwenkwesi knowledge model as a tool for defining the knowledge new project entrants require to become productive sooner when joining a project.

In response to the first objective, twelve knowledge types were analyzed. These knowledge types were tested in terms of how knowledgeable the project entrant felt before and after productivity was achieved. Lastly the new project entrant was required to rate how soon productivity was reached within the project.

Customer, Service, and Supplier knowledge were identified as the knowledge types that may have a strong impact on the time it takes to become productive during the course of the project. Acquiring these knowledge types during a project may reduce the time to productivity.

Technical, Process, People, Project Management, and Organisational knowledge types may have a strong positive impact on the time it takes the new entrant to become productive when entering a project. It is important to note, that these knowledge types may result in faster productivity times when the new project entrant enters the project knowledgeable in these areas. Gaining knowledge within these areas during the project has a lesser impact on the time to productivity compared to entering the project already knowledgeable in these areas.

Business Domain, Product, Environmental, and Institutional knowledge types were classified as Insignificant Knowledge areas. These results appear to show that being knowledgeable in these areas is not likely to reduce the amount of time it takes a new project entrant to become productive. These results are displayed irrespective of when knowledge in these areas was gained, i.e., before the project or during the project.

In response to the second objective, the Ink model is shown to be a moderately good model for identifying the knowledge types required by a new project entrant and definitely warrants further investigation. All the knowledge types required during the project, i.e., Customer, Service, and Supplier are covered by the model. Three of five knowledge types identified as knowledge types gained prior to the project that may reduce time to productivity are also included in the Ink model, i.e., Organisation, Process, and People. Lastly, only two out of four insignificant knowledge types are included in the Ink model: Environmental and Product. The Inkwenkwesi is identified as a good model to be used to identify the knowledge types required by a new project entrant to become productive sooner.

As the case with all research this one had limitations. Firstly, the sample was drawn from experienced IT project participants who had to recall and recount their experience when they were inexperienced project participants joining a new project. For some that experience had occurred 
years earlier and one has to question the completeness of their recollections. The second limitation is that the sample was drawn from a single organisation.

\section{References}

Campbell, D. J. (1988). Task complexity: A review and analysis. Academy of Management Review, 13(1), 40-52.

Chan, C., Jiang, J., \& Klein, G. (2008). Team task skills as a facilitator for application and development skills. IEEE Transactions on Engineering Management , 55(3), 434-441.

Chan, R., \& Rosemann, M. (2001). Managing knowledge in enterprise systems. Journal of Systems and Information Technology, 5(2), 37-54.

DeVellis, R. (2003). Scale development: Theory and applications (2nd ed.). Thousand Oaks, CA: Sage.

Disterer, G. (2002). Management of project knowledge and experiences. Journal of Knowledge Management, 6(5), 512-520.

Faraj, S., \& Sproull, L. (2000). Coordinating expertise in software development teams. Management Science, 46(12), 1554-1568.

Galloway, R. L., \& Whyte, G. (1989). The internal information systems function as a service operation. International Journal of Operations \& Production Management, 9(4), 19-27. doi:10.1108/EUM0000000001234

Gill, T. G. (2011). Informing with the case method. Santa Rosa, CA, USA: Informing Science Press.

Goles, T., Hawk, D., \& Kaiser, K. (2008). Information technology workforce skills: The software and IT services provider perspective. Information Systems Frontiers, 10(2), 179-194.

Kang, K., \& Hahn, J. (2009). Learning and forgetting curves in software development: Does type of knowledge matter? ICIS Proceedings. Paper 194. Retrieved 9 January 2012 from http://aisel.aisnet.org/icis2009/194

Karlsen, J., \& Gottschalk, P. (2004). Factors affecting knowledge transfer in IT projects. Engineering Management Journal, 6(1), 3-10.

Kasvi, J., Vartiainen, M., \& Hailikari, M. (2003). Managing knowledge and knowledge competences in projects and project organizations. International Journal of Project Management, 21(8), 571-582.

Lee, D., Trauth, E., \& Farwell, D. (1995). Critical skills and knowledge requirements of IS professionals: A joint academic-industry investigation. MIS Quarterly,19(3), 313-340.

Litwin, M. S. (1995). How to measure survey reliability and validity (Vol. 7). Sage.

Montiel, E. L. (2013). Online learning and case teaching: Implications in an informing systems framework. Online Learning : A Metaphor of Flash Mobs, 16, 261-272.

Reich, B. (2007). Managing knowledge and learning in IT projects: A conceptual framework and guidelines for practice. Project Management Journal, 38(2), 5-17.

Standish Group International. (2012). CHAOS Manifesto 2012: The year of the executive sponsor (p. 64). Retrieved from $\mathrm{http}: / /$ versionone.com/assets/img/files/CHAOSManifesto2012.pdf

Tiwana, A. (2004). An empirical study of the effect of knowledge integration on software development performance. Information and Software Technology, 46, 899-906.

Tiwana, A., Bharadwaj, A. S., \& Sambamurthy, V. (2003). The antecedents of information systems development capability in firms: A knowledge integration perspective. In ICIS (pp. 246-258).

Whyte, G. (1994). Understanding user perceptions of successful information systems. Doctoral dissertation, Cranfield University. 
Whyte G. (2011). Inkwenkwesi Knowledge Model. PowerPoint presentation distributed via email on 21 Monday 2011 (unpublished)

Whyte, G., \& Minnaar, D. (2013). Using the Inkwenkwesi model to identify the knowledge requirements of new project entrants. In International Conference of Information Management and Evaluation. Retrieved from http://academic-conferences.org/icime/icime2013/icime13-proceedings.htm

Yoo Y., \& Kanawattanachai, P. (2001). Developments of transaction memory systems and collection mind in virtual teams. International Journal of Organizational Analysis, 9(2), 187-208.

Zhao, D., \& Zuo, M. (2011). Knowledge transferred across projects and its characteristics in an IT service enterprise. Information Technology, Computer Engineering and Management Sciences (ICM), 2011 International Conference, vol. 3, pp. $267-270$

\section{Appendix: Survey Questionnaire}

1. What was the name of this project? *

\section{What was your role in the project?}

IT - Project Manager

O IT - Business Analyst

IT - Programmer/Developer

O IT - Architect

O IT - Tester

O Business - Subject Matter Expert

O Business - Project Manager / Sponsor

Business - Business/Process Analyst

O Business - Tester

O Business - User

Specify your own value:

\section{How long did it take you to become productive on the project? *}

$\bigcirc$ Less than 1 week

○ 2 weeks

○ 2 weeks - 1 month

O 1 - 2 months

greater than 3 months 


\section{Project Management Knowledge.}

This knowledge refers to knowledge of coordinating, planning organisation and controlling the project. *

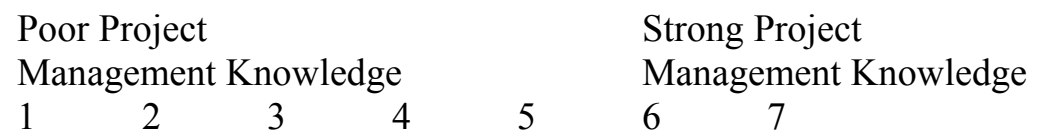

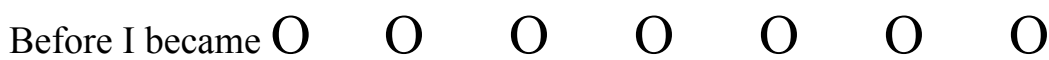

productive

$\begin{array}{llllllll}\text { After I became } & \mathrm{O} & \mathrm{O} & \mathrm{O} & \mathrm{O} & \mathrm{O} & \mathrm{O} & \mathrm{O}\end{array}$

productive

\section{Business Domain knowledge.}

This knowledge refers to knowledge about the business processes, business rules and activities, functional areas and operations. *

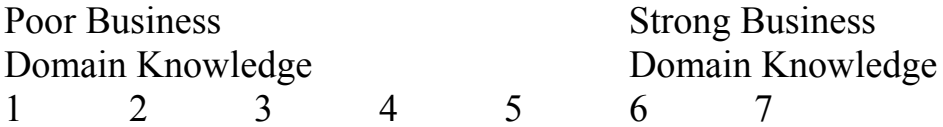

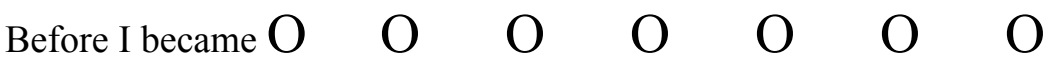
productive

$\begin{array}{llllllll}\text { After I became } & \mathrm{O} & \mathrm{O} & \mathrm{O} & \mathrm{O} & \mathrm{O} & \mathrm{O} & \mathrm{O}\end{array}$ productive

\section{Technical knowledge.}

This refers to technical know-how to implement information systems and involves the activities of the systems development life cycle. *

$\begin{array}{ll}\text { Poor Technical } & \text { Strong Technical } \\ \text { Knowledge } & \text { Knowledge }\end{array}$

$\begin{array}{cllllll}1 & 2 & 3 & 4 & 5 & 6 & 7 \\ \text { Before I became } \mathrm{O} & \mathrm{O} & \mathrm{O} & \mathrm{O} & \mathrm{O} & \mathrm{O} & \mathrm{O}\end{array}$ productive

$\begin{array}{llllllll}\text { After I became } & \mathrm{O} & \mathrm{O} & \mathrm{O} & \mathrm{O} & \mathrm{O} & \mathrm{O} & \mathrm{O}\end{array}$ productive

\section{Institutional knowledge.}

This refers to knowledge about values and culture of the organisation *

Poor Institutional

Knowledge$$
12
$$

Before I became $\mathrm{O}$

productive

After I became productive
Strong Institutional

Knowledge

$$
6 \quad 7
$$

00

O $\mathrm{O} \quad \mathrm{O} \quad \mathrm{O} \quad \mathrm{O}$

$\begin{array}{lllllll}\mathrm{O} & \mathrm{O} & \mathrm{O} & \mathrm{O} & \mathrm{O} & \mathrm{O} & \mathrm{O}\end{array}$ 


\section{Organisation knowledge.}

This knowledge refers to the knowledge of where in the organisation things are done or knowledge is kept. *

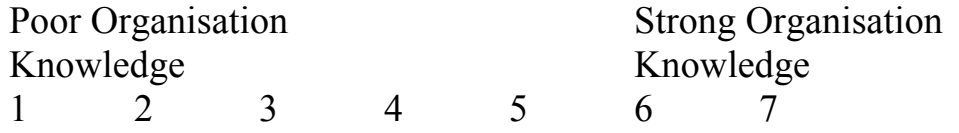

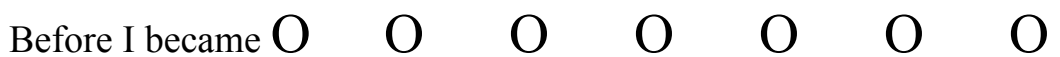

productive

$\begin{array}{lllllllll}\text { After I became } & \mathrm{O} & \mathrm{O} & \mathrm{O} & \mathrm{O} & \mathrm{O} & \mathrm{O} & \mathrm{O}\end{array}$

productive

\section{People Knowledge.}

This knowledge refers to the knowledge of important project and business stakeholders. *

Poor People Strong People

Knowledge Knowledge

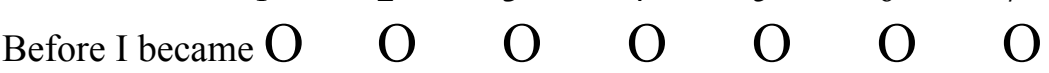
productive

$\begin{array}{llllllll}\text { After I became } & \mathrm{O} & \mathrm{O} & \mathrm{O} & \mathrm{O} & \mathrm{O} & \mathrm{O} & \mathrm{O}\end{array}$ productive

10. Process Knowledge.

This knowledge refers to the knowledge of the project processes to be adhered by the project within the organisation. *

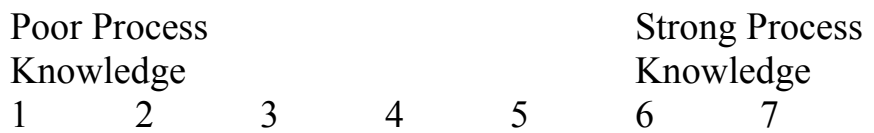

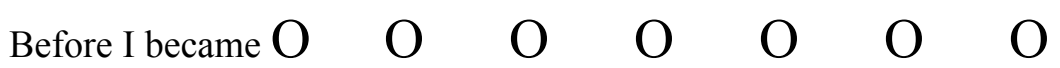
productive

$\begin{array}{llllllll}\text { After I became } & \mathrm{O} & \mathrm{O} & \mathrm{O} & \mathrm{O} & \mathrm{O} & \mathrm{O} & \mathrm{O}\end{array}$ productive

\section{Product Knowledge.}

This knowledge refers to the knowledge of the product being delivered by the project within the organisation. *

$\begin{array}{lllllll}\text { Poor Product } & & & \text { Strong Product } \\ \text { Knowledge } & & & & \begin{array}{l}\text { Knowledge } \\ \text { Know }\end{array} \\ 1 & 2 & 3 & 4 & 5 & 6 & 7\end{array}$

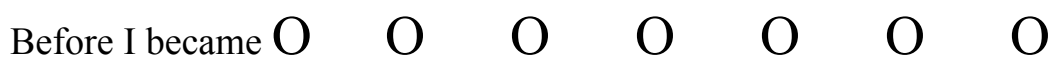
productive

$\begin{array}{llllllll}\text { After I became } & \mathrm{O} & \mathrm{O} & \mathrm{O} & \mathrm{O} & \mathrm{O} & \mathrm{O} & \mathrm{O}\end{array}$ productive 


\section{Service Knowledge.}

This knowledge refers to the knowledge of the services being delivered to the organisation by the project. *

Poor Service

Knowledge

Before I became $\mathrm{O}$

$$
2
$$

$\mathrm{O}$

$\mathrm{O}$

$\mathrm{O}$

0

Strong Service

productive

After I became $\mathrm{O}$

productive

\section{$\mathrm{O} \quad \mathrm{O} \quad \mathrm{O} \quad \mathrm{O}$}

Knowledge

$6 \quad 7$

$\mathrm{O} \mathrm{O}$

$\mathrm{O} \mathrm{O}$

\section{Customer Knowledge.}

This knowledge refers to the knowledge of the customer for whom the project is being delivered.

*

$\begin{array}{llllll}\text { Poor Customer } & & & \begin{array}{l}\text { Strong Customer } \\ \text { Knowledge }\end{array} \\ 1 & 2 & 3 & 4 & 5 & 6\end{array}$

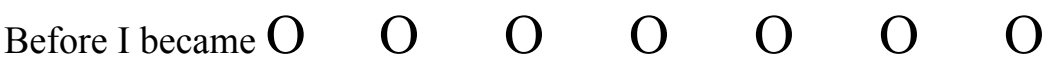
productive

$\begin{array}{llllllll}\text { After I became } & \mathrm{O} & \mathrm{O} & \mathrm{O} & \mathrm{O} & \mathrm{O} & \mathrm{O} & \mathrm{O}\end{array}$ productive

\section{Supplier Knowledge.}

This knowledge refers to the knowledge of any suppliers, third party vendors or service providers delivering a product/service to the project

\section{Poor Customer \\ Strong Customer}

Knowledge

1
Knowledge

$6 \quad 7$

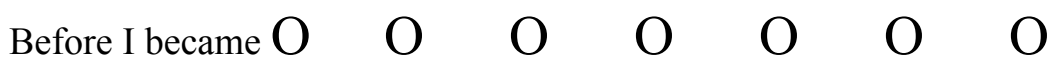
productive

$\begin{array}{llllllll}\text { After I became } & \mathrm{O} & \mathrm{O} & \mathrm{O} & \mathrm{O} & \mathrm{O} & \mathrm{O} & \mathrm{O}\end{array}$ productive

\section{Environment Knowledge.}

This refers to knowledge of the macro environment,( e.g. Industry \& Market) in which the project operates within the organisation. *

Poor Environment

Knowledge$$
1
$$

Before I became $\mathrm{O} \quad 2$

productive

After I became

productive
Strong Environment

Knowledge

$6 \quad 7$

$\begin{array}{lllll}\mathrm{O} & \mathrm{O} & \mathrm{O} & \mathrm{O} & \mathrm{O}\end{array}$

$\begin{array}{lllllll}\mathrm{O} & \mathrm{O} & \mathrm{O} & \mathrm{O} & \mathrm{O} & \mathrm{O} & \mathrm{O}\end{array}$ 
16. Please identify on any key areas of knowledge you required to become productive quickly. *

17. Please rate overall the time it took you to become productive on the project *

Very Slowly

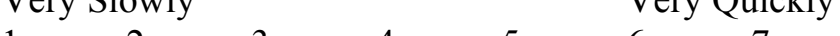

$\begin{array}{lllllll}1 & 2 & 3 & 4 & 5 & 6 & 7\end{array}$

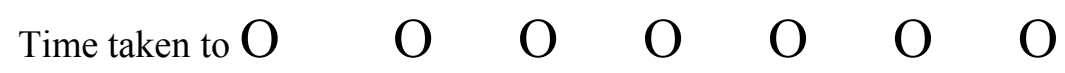

\section{Biographies}

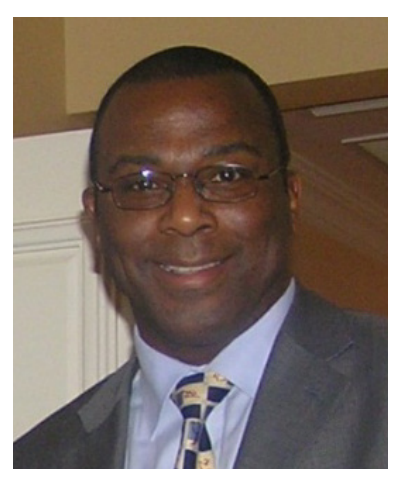

Grafton Whyte is Director of the Harold Pupkewitz Graduate School of Business, Polytechnic of Namibia. He obtained his PhD at Cranfield University, UK in information systems management and MBA at Westminster University, London.

He has worked as Finance \& Operations Director for Zimele Sonke Technologies in Cape Town, Founder \& CEO of Service Management Consultants in the UK and UK Systems Development Manager for Reuters. His main research interests are in information and knowledge management.

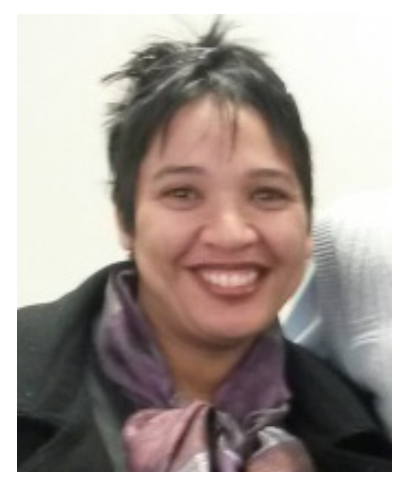

Desiré Minnaar was born in Cape Town, South Africa in 1980. She received the B.Com in Information Systems (Cum Laude) in 2008 and the B.Com in Information Systems (Honours) (Cum Laude) in 2012 from the University of the Western Cape. Since 2009 she has been a Senior Business Analyst in the Financial Services industry in South Africa. Her professional experience includes software development, business analysis and project management in municipal governance, retail, health services and the financial services industry. 